\title{
Produção de biomassa e teores de carbono, hidrogênio, nitrogênio e proteína em microalgas
}

\author{
Production of biomass and carbon, hydrogen, nitrogen and protein contents in microalgae
}

\author{
Silvana Ohse ${ }^{\mathrm{I}}$ Roberto Bianchini Derner ${ }^{\mathrm{II}}$ Renata Ávila Ozório ${ }^{\mathrm{II}}$ \\ Maurício Villela Da Costa BragaII Paulo Cunha ${ }^{\text {III }}$ Cláudia Pavan Lamarca ${ }^{\text {III }}$ \\ Márcia Estevão Dos Santos ${ }^{\text {III }}$
}

\section{RESUMO}

$\mathrm{O}$ aumento da emissão de $\mathrm{CO}_{2}$ e de outros gases efeito estufa tem gerado debates em nível mundial sobre alterações climáticas e estimulado o desenvolvimento de estratégias mitigadoras. Trabalhos nessa área incluem sequestro de $\mathrm{CO}_{2}$ por meio da produção de microalgas aquáticas. Por essa razão, desenvolveu-se um estudo visando determinar os teores de carbono, hidrogênio, nitrogênio e proteína e a produção de biomassa seca de nove espécies de microalgas marinhas (Nannochloropsis oculata, Thalassiosira pseudonana, Phaeodactylum tricornutum, Isochrysis galbana, Tetraselmis suecica, Tetraselmis chuii Chaetoceros muelleri, Thalassiosira fluviatilis e Isochrysis sp.) e uma de água doce (Chlorella vulgaris), em cultivo autotrófico estacionário com objetivo de identificar as mais produtivas e com maior capacidade de fixação de carbono. O experimento foi desenvolvido em sala de cultivo, na Universidade Federal de Santa Catarina, com iluminação contínua e radiação em torno de $150 \mu \mathrm{mol} \mathrm{m} \mathrm{m}^{-2} \mathrm{~s}^{-1}$, temperatura de $25 \pm 2^{\circ} \mathrm{C}$, suplementação de ar constante, sendo utilizados erlenmeyers com $800 \mathrm{~mL}$ de meio de cultura. $O$ delineamento experimental foi de blocos casualizados no tempo com três repetições. As espécies $\boldsymbol{C}$. Vulgaris e T. suecica são menos produtivas. Quando se visa à suplementação alimentar, as espécies $\boldsymbol{C}$. vulgaris $e$ T. Chuii são consideradas interessantes, uma vez que apresentam altos teores de $C, N$, $H$ e proteína. As espécies $N$. Oculata, T. pseudonana e C. vulgaris apresentam altos teores de $C$, demonstrando alta capacidade de fixação de carbono.

Palavras-chave: composição química, produtividade, fitoplâncton.

\begin{abstract}
The increase of $\mathrm{CO}_{2}$ emission and other gases greenhouse effect, caused global debates about climatic alterations and stimulated the development of mitigative strategies. Researches in this area includes $\mathrm{CO}_{2}$ kidnapping through the aquatic microalgae production. For this reason, a study was developed aiming to determine the production of dry biomass, carbon content, hydrogen, nitrogen and rate protein growth of nine marine microalgae species (Nannochloropsis oculata, Thalassiosira pseudonana, Phaeodactylum tricornutum, Isochrysis galbana, Tetraselmis suecica, Tetraselmis chuii, Chaetoceros muelleri, Thalassiosira fluviatilis and Isochrysis sp.) and one freshwater species (Chlorella vulgaris) under stationary autotrophy conditions. Erlenmeyers flasks with $800 \mathrm{~mL}$ medium culture were exposed to constant light intensity and air flow, photon flux density of about $150 \mu \mathrm{mol} \mathrm{m} \mathrm{m}^{-2} \mathrm{~s}^{-1}$ and $25 \pm 2^{\circ} \mathrm{C}$ temperature were used in the experiment The delineating experiment was carried out in a randomized block over time with three replicates. The species C. Vulgaris and T. suecica are less productive. When the aim is the alimentary supplementation, the species $C$. vulgaris and $\mathbf{T}$. Chuii are considered interesting, since it presents high contents of $C, N, H$ and protein. The species $N$. Oculata, T. pseudonana and $\boldsymbol{C}$. vulgaris present high contents of $C$, demonstrating high capacity of carbon setting.
\end{abstract}

Key words: chemist composition, productivity, phytoplankton.

\section{INTRODUÇÃO}

As algas são consideradas os organismos mais antigos da Terra, havendo evidências de sua

IDepartamento de Fitotecnia e Fitossanidade, Setor de Ciências Agrárias e Tecnologia, Universidade Estadual de Ponta Grossa (UEPG), 84030-900, Ponta Grossa, PR, Brasil. E-mail: sohse@uepg.br. Autor para correspondência.

"Engenharia de Aquicultura, Centro de Ciências Agrárias (CCA), Universidade Federal de Santa Catarina (UFSC), Florianópolis, SC, Brasil.

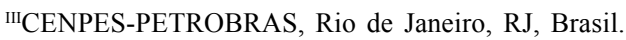


existência já no pré-cambriano, há aproximadamente 3,5 bilhões de anos. Possivelmente foram as responsáveis pela produção e pelo acúmulo de $\mathrm{O}_{2}$ na atmosfera primitiva, desempenhando, ainda hoje, papel importante na manutenção dos níveis desse gás, especialmente as formas marinhas planctônicas. Além disso, as algas têm sido reconhecidas como os organismos que deram origem a todos os outros organismos vegetais existentes atualmente (RAVEN et al., 2001).

Geralmente, quando se fala em produção de biomassa, dada pela incorporação de $\mathrm{CO}_{2}$, são citadas as plantas arbóreas e arbustivas e as culturas agrícolas, ou seja, somente os seres pertencentes ao Reino Plantae, esquecendo-se que as cianobactérias (Reino Monera) foram as grandes responsáveis pelo aumento do teor de $\mathrm{O}_{2}$ na atmosfera e, também as algas (Reino Protista). O processo responsável pela incorporação de $\mathrm{CO}_{2}$ é a fotossíntese, resultando em liberação de $\mathrm{O}_{2}$ para a atmosfera e acúmulo de biomassa pelo ser autotrófico. Os oceanos e não as florestas são o verdadeiro pulmão do mundo. Isso se deve ao fato de nosso planeta possuir cerca de $67 \%$ de sua superfície recoberta com água, a qual é habitada por uma grande diversidade de seres planctônicos autotróficos chamados microalgas.

As microalgas aquáticas são reconhecidas por apresentarem eficiência fotossintética superior às plantas $\mathrm{C}_{4}$, taxas de proliferação rápida, grande variedade de tolerância a ambientes extremos, além de apresentarem excelente adaptabilidade a cultivos intensivos, o que as torna eficazes na redução do $\mathrm{CO}_{2}$ atmosférico (KURANO et al., 1995). Dos organismos fotossintetizantes, as microalgas são muito mais eficientes no uso do $\mathrm{CO}_{2}$ que as plantas superiores, podendo fixar quantidades muito maiores de $\mathrm{CO}_{2}$ por área de terra. Assim, máximas produtividades de plantas superiores e árvores estão restritas a áreas com solo, água e clima favoráveis. A exposição das folhas à atmosfera submete-as a variações da demanda evaporativa, o que pode minimizar o processo fotossintético e, com isso, a absorção de $\mathrm{CO}_{2}$. Microalgas em cultivo massal não se encontram sujeitas à inibição fotossintética, uma vez que o conteúdo de água pode ser controlado pela própria engenharia, o que explica sua superioridade quanto à capacidade de absorção de $\mathrm{CO}_{2}$ quando comparadas a plantas superiores (BROWN \& ZEILER, 1993).

As microalgas vêm sendo utilizadas na alimentação de animais aquáticos; como fonte de proteínas na forma de suplementação alimentar; como fonte de pigmentos (ficocianinas, astaxantinas e $\beta$ caroteno); tratamento de águas residuais; como adubo orgânico e, atualmente, vêm sendo indicadas como uma possível matéria-prima para biocombustíveis, devido ao alto teor de óleo que algumas espécies apresentam e ao perfil de ácidos graxos.

Devido à alta produtividade, ao rápido crescimento de várias espécies de microalgas e ao grande número de substâncias de altíssimo interesse econômico por elas produzidas, a pesquisa acerca dessas microalgas tem aumentado. Todavia, no Brasil, estudos com esses microrganismos ainda são incipientes. Por essa razão, desenvolveu-se um ensaio laboratorial em sistema autotrófico estacionário a fim de conhecer a produtividade e os teores de carbono, hidrogênio, nitrogênio e proteína de 10 espécies de microalgas, sendo uma de água doce e nove marinhas.

\section{MATERIAL E MÉTODOS}

O experimento foi desenvolvido em sala de cultivo do Departamento de Ciência dos Alimentos (CAL) da Universidade Federal de Santa Catarina (UFSC), em Florianópolis, Santa Catarina (SC). As microalgas estudadas foram: Chlorella vulgaris de água doce, Nannochloropsis oculata, Thalassiosira pseudonana, Phaeodactylum tricornutum, Isochrysis galbana, Tetraselmis suecica, Tetraselmis chui, Chaetoceros muelleri, Thalassiosira fluviatilis e Isochrysis sp. de ambiente marinho. O delineamento experimental utilizado foi de blocos casualizados no tempo, com três repetições, perfazendo 30 unidades experimentais. O experimento foi desenvolvido durante os meses de agosto e dezembro de 2004.

Durante a fase experimental, a sala de cultivo foi mantida sob temperatura de $25 \pm 2^{\circ} \mathrm{C}$ e com radiação artificial contínua das culturas $\left( \pm 75 \mu \mathrm{mol} \mathrm{m} \mathrm{m}^{-2} \mathrm{~s}^{-1}\right.$ no primeiro dia de cultivo, passando a $\pm 150 \mu \mathrm{mol} \mathrm{m}^{-2} \mathrm{~s}^{-1} \mathrm{a}$ partir do segundo dia até a coleta, a qual foi fornecida por lâmpadas fluorescentes de $40 \mathrm{~W}$ da marca OSRAM). Para o cultivo da espécie C. vulgaris, foi utilizado o meio de cultura W.C., utilizado para algas verde-amarelas (Tabela 1) e para as espécies marinhas o meio F/2 Guillard (Tabela 2), cuja salinidade foi de $29 \%$. As culturas foram aeradas por meio de um minicompressor (Oxi-bolha).

A fase experimental constou da inoculação de um volume pré-determinado de inóculo em função da densidade inicial desejada, em $800 \mathrm{~mL}$ de meio de cultura W.C (Tabela 1), para a cepa de água doce, e meio F/2 Guillard (Tabela 2), para as cepas marinhas. Como unidade experimental, foram utilizados erlenmeyers de $1000 \mathrm{~mL}$. O volume de $800 \mathrm{~mL}$ era adicionado aos erlenmeyers de $1000 \mathrm{~mL}$, autoclavados por 30 minutos a $121^{\circ} \mathrm{C}$ e, então, armazenados por 48 
Tabela 1 - Meio de cultura W.C., modificado de GUILLARD \& LORENZEN (1972).

\begin{tabular}{|c|c|c|}
\hline Reagentes & Solução-estoque $\left(\mathrm{g} 100 \mathrm{~mL}^{-1}\right)$ & Meio de cultura \\
\hline $\mathrm{CaCl}_{2} \cdot 2 \mathrm{H}_{2} \mathrm{O}$ & 36,8 & $1 \mathrm{~mL}$ \\
\hline $\mathrm{MgSO}_{4} .7 \mathrm{H}_{2} \mathrm{O}$ & 37,0 & $1 \mathrm{~mL}$ \\
\hline $\mathrm{Na}_{2} \mathrm{HCO}_{3}$ & 12,6 & $1 \mathrm{~mL}$ \\
\hline $\mathrm{K}_{2} \mathrm{HPO}_{4} \cdot 3 \mathrm{H}_{2} \mathrm{O}$ & 11,4 & $1 \mathrm{~mL}$ \\
\hline $\mathrm{NaNO}_{3}$ & 85,0 & $1 \mathrm{~mL}$ \\
\hline $\mathrm{Na}_{2} \mathrm{SiO}_{3} .5 \mathrm{H}_{2} \mathrm{O}$ & 21,2 & $1 \mathrm{~mL}$ \\
\hline \multirow{3}{*}{ Solução de Ferro } & (g 1000 $\mathrm{mL}^{-1}$ de água destilada) & $1 \mathrm{~mL}$ \\
\hline & $\mathrm{Na}_{2}$ EDTA $=4,36$ & \\
\hline & $\mathrm{FeCl}_{3} \cdot \mathrm{H}_{2} \mathrm{O}=3,15$ & \\
\hline \multirow{4}{*}{$\begin{array}{l}\text { Solução micronutrientes } \mathrm{MnCl}_{2} \cdot 4 \mathrm{H}_{2} \mathrm{O}=0,18 \\
\mathrm{Na}_{2} \mathrm{MoO}_{4} \cdot 2 \mathrm{H}_{2} \mathrm{O}=0,006 \\
\mathrm{H}_{3} \mathrm{BO}_{3}=1,0\end{array}$} & (g 1000 $\mathrm{mL}^{-1}$ de água destilada) & $1 \mathrm{~mL}$ \\
\hline & $\mathrm{CuSO}_{4} .5 \mathrm{H}_{2} \mathrm{O}=0,01$ & \\
\hline & $\mathrm{ZnSO}_{4} \cdot 7 \mathrm{H}_{2} \mathrm{O}=0,022$ & \\
\hline & $\mathrm{CoCl}_{2} . \mathrm{H}_{2} \mathrm{O}=0,01$ & \\
\hline \multirow{3}{*}{ Solução vitaminas } & (g 1000 $\mathrm{mL}^{-1}$ de água destilada) & $1 \mathrm{~mL}$ \\
\hline & Tiamina $\mathrm{HCl}=0,1$ & \\
\hline & Biotina $=0,0005$ & \\
\hline Água destilada & & $1000 \mathrm{~mL}$ \\
\hline
\end{tabular}

horas a $25^{\circ} \mathrm{C}$, em razão da instalação de cada repetição. Efetuou-se a correção do $\mathrm{pH}$ do meio de cultura de água doce para 6,5 , com solução de $\mathrm{HCl} 10 \%( \pm 2 \mathrm{~mL})$ e de água marinha manteve-se em torno de $\pm 8,0$, não havendo necessidade de correção.

Para a produção de inóculo, foi realizada a repicagem das espécies mantidas em tubos de ensaio contendo $10 \mathrm{~mL}$ de cultura para erlenmeyers contendo $100 \mathrm{~mL}$ de cultura. Estes foram acondicionados em sala de cultivo, sob temperatura de $25 \pm 2^{\circ} \mathrm{C}$, radiação de $\pm 50 \mu \mathrm{mol} \mathrm{m} \mathrm{m}^{-2} \cdot \mathrm{s}^{-1}$. Após três dias de crescimento nessas condições, esse volume foi repassado para erlenmeyers de $500 \mathrm{~mL}$ contendo $300 \mathrm{~mL}$ de meio de cultura mantidos sob radiação de aproximadamente $75 \mu \mathrm{mol} \mathrm{m}^{-2} \mathrm{~s}^{-1}$, onde permaneceram por mais três dias, visando aumentar a população, ou seja, a fonte de inóculo. Então foi determinada a densidade celular das culturas e quantificado o volume a ser inoculado em cada unidade experimental (no volume de $800 \mathrm{~mL}$ ).

Em razão da coleta de cada unidade experimental, o volume de cada erlenmeyer foi centrifugado duas vezes sob temperatura de $10^{\circ} \mathrm{C}$, por 20 minutos a 4.000rpm. As amostras foram congeladas e liofilizadas, quando se determinou a biomassa seca e, desta, realizou-se a análise do teor de carbono, hidrogênio e nitrogênio, por meio da análise elementar CHNS. O teor de proteína foi derivado do teor de $\mathrm{N}$ encontrado na biomassa seca, utilizando-se o fator de conversão 6,25 . O tamanho celular obtido foi de 2,03; $5,18 \times 3,15 ; 4,8 \times 3,15 ; 5,33 \times 3,15 ; 15,68 \times 2,33 ; 5,25 \times 3,52$; $9,51 \times 5,7 ; 10,88 \times 7,2$ e $1,93 \times 8,03 \mu \mathrm{m}$, respectivamente, para Nannochloropsis oculata (forma esférica), Isochrysis galbana, Isochrysis sp., Chaetoceros muelleri, Phaeodactylum tricornutum, Thalassiosira pseudonana, Tetraselmis suecica, Thalassiosira fluviatilis e Tetraselmis chui.

Os dados obtidos para produtividade e teores de $\mathrm{C}, \mathrm{H}, \mathrm{N}$ e proteína foram submetidos à análise estatística por meio de análise de variância e teste de Tukey, em nível de 5\% de significância, a fim de identificar diferenças entre as médias de cada tratamento, utilizando-se, para isso, o programa ESTAT.

\section{RESULTADOS E DISCUSSÃO}

A análise de variância revelou significância para o efeito dos tratamentos na variável biomassa seca (BMS). A espécie $\boldsymbol{C}$. vulgaris apresentou menor valor de BMS L ${ }^{-1}$ (gramas de BMS por litro de cultura), não diferindo significativamente das espécies $\boldsymbol{P}$. tricornutum, T. chuii e T. suecica e produzindo 52,90\% a menos que $N$. Oculata (Tabela 3). Segundo MINOWA \& SAWAYAMA (1999), as microalgas apresentam alto teor de água, com produtividades variando de 0,5 a 1,0g BMS L $\mathrm{g}^{-1}$. Exceto T. suecica e C. vulgaris, as demais se apresentam dentro da faixa indicada pelos referidos

Ciência Rural, v.39, n.6, set, 2009. 
Tabela 2 - Composição do meio de cultura F/2 empregado no cultivo de microalgas marinhas.

\begin{tabular}{|c|c|}
\hline \multicolumn{2}{|c|}{ Solução de nitrato (adicionar $0,65 \mathrm{~mL} \mathrm{~L}^{-1}$ de água do mar) } \\
\hline $\mathrm{NaNO}_{3}$ & $150,0 \mathrm{~g}$ \\
\hline $\mathrm{FeCl}_{3} \cdot 6 \mathrm{H}_{2} \mathrm{O}$ & $8,0 \mathrm{~g}$ \\
\hline EDTA Na 2 & $10,0 \mathrm{~g}$ \\
\hline Sol. Traços de Metais & 2,0mL (de cada solução) \\
\hline Água destilada & a $1,0 \mathrm{~L}$ \\
\hline $\mathrm{ZnCl}_{2} .7 \mathrm{H}_{2} \mathrm{O}$ & $1,65 \mathrm{~g}$ \\
\hline $\mathrm{CoCl} 2.6 \mathrm{H}_{2} \mathrm{O}$ & $1,50 \mathrm{~g}$ \\
\hline$\left(\mathrm{NH}_{4}\right)_{6} \mathrm{Mo}_{7} \mathrm{O}_{24} \cdot 4 \mathrm{H}_{2} \mathrm{O}$ & $0,60 \mathrm{~g}$ \\
\hline $\mathrm{CuSO}_{4} .5 \mathrm{H}_{2} \mathrm{O}$ & $1,47 \mathrm{~g}$ \\
\hline $\mathrm{MnCl}_{2} \cdot 6 \mathrm{H}_{2} \mathrm{O}$ & $27,0 \mathrm{~g}$ \\
\hline Água destilada para cada solução & $150,0 \mathrm{~mL}$ \\
\hline $\mathrm{NaH}_{2} \mathrm{PO}_{4} \cdot \mathrm{H}_{2} \mathrm{O}$ & $16,0 \mathrm{~g}$ \\
\hline Água destilada & a $1,0 \mathrm{~L}$ \\
\hline Silicato de sódio (H-300, QUIMIDROL) & $80,0 \mathrm{~g}$ \\
\hline Água destilada & a $1,0 \mathrm{~L}$ \\
\hline Tris (Hidroximetil) Aminometano & $50,0 \mathrm{~g}$ \\
\hline Ácido clorídrico PA & $35,0 \mathrm{~mL}$ \\
\hline Água destilada & $470,0 \mathrm{~mL}$ \\
\hline Adicionar $5,0 \mathrm{~mL} \mathrm{~L}^{-1}$ de água do mar, qua & clavar o meio. \\
\hline Vitaminas: & \\
\hline Biotina: $0,1 \mathrm{~g}$ para $100 \mathrm{~mL}$, deste adiciono & sfato. \\
\hline Cianocobalamina: $0,1 \mathrm{~g}$ para $100 \mathrm{~mL}$, dest & ıção de Fosfato. \\
\hline Tiamina: $0,2 \mathrm{~g}$, adicionada à solução de $\mathrm{Fc}$ & \\
\hline
\end{tabular}

Fonte: GUILLARD (1975).

autores (Tabela 3). A espécie $\boldsymbol{N}$. Oculata apresenta forma esférica, com diâmetro médio de $2,03 \mu \mathrm{m}$, sendo menor que as demais espécies estudadas, fator que pode justificar seu desempenho em produtividade, uma vez que sua densidade poderá ser bem maior e, como as microalgas são compostas basicamente de água, quanto maior o número de indivíduos (células) maior a BMS. Além disso, as espécies pertencem a diferentes classes taxonômicas, apresentando, com isso, características genéticas, dimensões e morfologias diferentes.

O valor de BMS obtido para o gênero Nannochloropsis não diverge muito do obtido por RODOLFI et al. (2003), sendo, porém, significativamente superior ao encontrado por ROCHA et al. (2003), os quais foram $1 \mathrm{~g} \mathrm{BMS} \mathrm{L}{ }^{-1}$ e $0,38 \mathrm{~g} \mathrm{BMS} \mathrm{L}^{-1}$, respectivamente. Extrapolando o valor obtido pela $N$. oculata para um tanque de 1 ha $(100 \times 100 \mathrm{~m})$ e $0,3 \mathrm{~m}$ de profundidade $\left(3.000 \mathrm{~m}^{3}\right)$, tem-se $3.000 .000 \mathrm{~L}$ de cultivo. Considerando a produtividade obtida neste estudo, ter-se-ia 2,48t BMS ha-1 de $N$. Oculata. Se realizados 12 cultivos ao ano, obter-se-ia 29,81t de BMS ha- $\mathrm{a}^{-1}$ (Tabela 3). Além disso, o ciclo da N. Oculata foi de sete dias, o que propicia o aumento do número de cultivos por mês e, consequentemente, por ano.

Estudando o crescimento de 18 espécies de microalgas sob condições controladas, RENAUD et al. (1999) encontraram 43, 47,6 e 32,1 pg BMS cel ${ }^{-1}$ para Chaetoceros sp., Tetraselmis sp. e Isochrysis sp., respectivamente. No presente trabalho, houve semelhança de produtividade dos gêneros Chaetoceros sp. e Isochrysis sp. e superioridade do gênero 
Tabela 3 - Lista das espécies de microalgas estudadas e respectiva produção de biomassa seca por litro de cultura (mg BMS $\mathrm{L}^{-1}$ ), por célula (os dados de BMS de $\mathrm{mg} \mathrm{L}^{-1}$ foram transformados para $\mathrm{g} \mathrm{mL}^{-1}$ e divididos pela densidade celular máxima (DCM)), por $\mathrm{m}^{-3} \mathrm{~d}^{-1}$ (extrapolou-se a BMS encontrada por litro de cultivo para $1000 \mathrm{~L}\left(1 \mathrm{~m}^{3}\right)$, dividindo-se o resultado pelo dia de cultivo que atingiu a DCM para cada espécie) e por $\mathrm{L} \mathrm{d}^{-1}$ (os dados de BMS foram divididos pelo dia de cultivo que atingiu a DCM para cada espécie). O desvio padrão é colocado entre parênteses após as médias.

\begin{tabular}{|c|c|c|c|c|}
\hline Espécie & mg BMS L ${ }^{-1}$ & pg BMS cel ${ }^{-1}$ & $\mathrm{~g} \mathrm{BMS} \mathrm{m}^{-3} \mathrm{~d}^{-1}$ & g BMS L ${ }^{-1} d^{-1}$ \\
\hline Nannochloropsis oculata & $828,03(140,54) \mathrm{a}^{*}$ & 14,945 & 118,29 & 0,12 \\
\hline Chaetoceros muelleri & $801,12(182,68) a$ & 49,595 & 141,29 & 0,14 \\
\hline Thalassiosira fluviatilis & $794,42 \quad(16,71) a$ & 484,40 & 183,47 & 0,18 \\
\hline Isochrysis galbana & $730,85 \quad(76,79) \mathrm{a}$ & 29,26 & 146,17 & 0,15 \\
\hline Thalassiosira pseudonana & $679,11(106,16) a b$ & 63,15 & 169,78 & 0,17 \\
\hline Isochrysis sp. & $676,55(156,73) a b$ & 28,05 & 112,76 & 0,11 \\
\hline Phaeodactylum tricornutum & $618,84(155,54) a b c$ & 41,74 & 103,14 & 0,10 \\
\hline Tetraselmis chuii & $612,82 \quad(60,65) a b c$ & 557,10 & 114,98 & 0,11 \\
\hline Tetraselmis suecica & $406,73 \quad(22,99) \quad b c$ & 191,55 & 81,35 & 0,08 \\
\hline Chlorella vulgaris & $390,01 \quad(18,84) \quad \mathrm{c}$ & 505,19 & 58,47 & 0,06 \\
\hline Média geral & 653,85 & 196,50 & 122,97 & 0,122 \\
\hline $\mathrm{CV}(\%)$ & 14,52 & & & \\
\hline
\end{tabular}

*Tratamentos com médias não seguidas pela mesma letra diferem entre si, pelo teste de Tukey, em nível de 5\% de probabilidade de erro.

Tetraselmis. Valores inferiores foram reportados também por RENAUD et al. (2002) para Chaetoceros sp. e Isochrysis sp., com produtividades de 25,0pg BMS cel $^{-1}$ e 20,8pg BMS cel ${ }^{-1}$, respectivamente (Tabela 3).

Produtividade inferior para C. muelleri, em razão do cultivo em sistema estacionário protegido durante o verão-outono $\left(26,1 \mathrm{~g} \mathrm{BMS} \mathrm{m}^{-3} \mathrm{~d}^{-1}\right)$ e invernoprimavera $\left(43,7 \mathrm{~g}\right.$ BMS $\left.\mathrm{m}^{-3} \mathrm{~d}^{-1}\right)$, foi reportada por LÓPEZ-ELÍAS et al. (2005), o que pode ser justificada pela iluminação contínua (24 horas) mantida no presente trabalho, o que mantém as microalgas fotossintetizando 24 horas por dia, intensificando seu crescimento e, com isso, o acúmulo de BMS (Tabela 3). No entanto, GÖKSAN et al. (2003) encontraram valor médio semelhante $\left(0,16 \mathrm{~g} \mathrm{BMS} \mathrm{L}^{-1} \mathrm{~d}^{-1}\right)$ ao obtido neste estudo para C. muelleri (Tabela 3).

O valor médio observado para $\boldsymbol{P}$. tricornutum encontra-se dentro da faixa de 0,57 a $2,10 \mathrm{~g}$ BMS L ${ }^{-1}$ obtida por GARCÍA et al. (2005) em cultivo mixotrófico. Todavia, esse valor é inferior ao encontrado por FERNÁNDEZ et al. (2003), quando cultivada em reator a céu aberto (Tabela 3 ).

O valor de 180,2.pg BMS cel ${ }^{-1}$ foi obtido para T. suecica por NIEVES et al. (2005), corroborando o resultado obtido neste trabalho para a mesma espécie (Tabela 3). Exceto T. suecica e C. vulgaris, as demais espécies apresentaram produtividades superiores, porém em distintas condições laboratoriais (Tabela 3).

Para a microalga $C$. vulgaris, a literatura apresenta valores de BMS inferiores e superiores (SCRAGG et al., 2002; WATANABE \& SAIKI, 1996, respectivamente). Já para I. Galbana valor inferior foi observado por TZOVENIS et al. (2003). Produtividade superior à média geral deste estudo foi observada em diferentes espécies microalgais e condições de cultivo (KURANO et al., 1995; RICHMOND et al., 2003; OLAIZOLA, 2003). As diferenças de produtividade se devem provavelmente a variações experimentais, sejam elas de radiação, temperatura, aeração, meio de cultura, tipo de cultivo, tempo de cultivo, etc. $\mathrm{O}$ acúmulo de BMS, em cultivos estacionários, varia bastante, além de apresentar altíssimo custo de produção, o qual representa cerca de $30 \%$ do custo total de produção de alimento vivo (VALENZUELA-ESPINOZA et al., 1999). Houve significância nos tratamentos para teor de carbono (C) na BMS. A espécie $N$. oculata apresentou o maior teor, diferindo significativamente somente da espécie I. galbana, da qual apresentou superioridade de 56,14\% (Tabela 4). O teor de C apresentado por $N$. oculata encontra-se mais próximo ao valor de $45 \%$ citado por RAVEN et al. (2001), para plantas superiores. Como o C é um componente estrutural, era de se esperar pequena variação entre as espécies de microalgas estudadas.

A espécie $N$. oculata apresentou 40,85\% de $\mathrm{C}$ na BMS, sendo inferior ao encontrado por MINOWA et al. (1995) para Dunaliella tertiolecta. MIAO \& WU (2004) e MIAO et al. (2004), cultivando Chlorella protothecoides em cultivo autotrófico e heterotrófico, obtiveram teores superiores ao obtido neste estudo para $\boldsymbol{C}$. vulgaris. Da mesma forma, WATANABE \& SAIKI (1996), cultivando Chlorella sp., constataram

Ciência Rural, v.39, n.6, set, 2009. 
Tabela 4 - Lista das espécies de microalgas estudadas e respectivos teores de carbono (TCBMS), de nitrogênio (TNBMS), de hidrogênio (THBMS) e de proteína na biomassa seca (TPBMS em \% ou mg $100 \mathrm{~g}^{-1}$ ). O desvio padrão é colocado entre parênteses após as médias.

\begin{tabular}{|c|c|c|c|c|}
\hline Espécie & TCBMS (\%) & TNBMS (\%) & THBMS (\%) & TPBMS (\%) \\
\hline Nannochloropsis oculata & $40,85(10,66) \mathrm{a}$ & $4,62(1,73) a b$ & $6,98(0,83) \mathrm{a}$ & $28,88(10,81) \mathrm{ab}$ \\
\hline Chaetoceros muelleri & $34,81(0,86) a b$ & $2,77(0,42) b$ & $4,05(0,65) \mathrm{e}$ & $17,32 \quad(2,61) b$ \\
\hline Thalassiosira fluviatilis & $31,77(3,20) a b$ & $3,11(0,91) b$ & $5,06(0,09)$ cde & $19,44 \quad(5,69) b$ \\
\hline Isochrysis galbana & $22,93(4,27) b$ & $2,91(0,70) b$ & $4,24(0,42) \mathrm{de}$ & $18,16(4,35) b$ \\
\hline Thalassiosira pseudonana & $38,86(5,09) \mathrm{a}$ & $4,81(2,42) a b$ & $5,40(1,00)$ bcde & $30,02(15,15) a b$ \\
\hline Isochrysis sp. & $34,16(6,78) a b$ & $4,93(0,59) a b$ & $5,07(0,22)$ cde & $30,81(3,68) a b$ \\
\hline Phaeodactylum tricornutum & $35,05(3,49) a b$ & $3,20(1,26) b$ & $4,93(0,53)$ cde & $20,00 \quad(7,90) b$ \\
\hline Tetraselmis chuii & $36,84(2,83) a b$ & $6,65(0,91) \mathrm{a}$ & $6,58(0,40) a b$ & $41,54(5,68) \mathrm{a}$ \\
\hline Tetraselmis suecica & $37,54(5,26) a b$ & $4,38(1,38) a b$ & $6,08(0,75) \mathrm{abc}$ & $27,39 \quad(8,60) a b$ \\
\hline Chlorella vulgaris & $39,09(4,07) \mathrm{a}$ & $5,30(1,51) a b$ & $5,85(0,21)$ abcd & $33,15(9,41) \mathrm{ab}$ \\
\hline Média geral & 35,19 & 3,27 & 5,42 & 26,67 \\
\hline CV (\%) & 14,58 & 31,94 & 9,92 & 24,49 \\
\hline
\end{tabular}

*Tratamentos com médias não seguidas pela mesma letra diferem entre si, pelo teste de Tukey, em nível de 5\% de probabilidade de erro.

$46,1 \%$ de $\mathrm{C}$ na BMS, valor $15,21 \%$ superior ao obtido neste trabalho para o mesmo gênero (Tabela 4). MASAKAZU \& IKENOUCHI(1997) encontraram como valor médio de $1 \mathrm{~g} \mathrm{CO}_{2} \mathrm{~L}^{-1} \mathrm{~d}^{-1}$ com radiação contínua. KURANO et al. (1995), em Chlorococcum littorale, obtiveram teor de $\mathrm{CO}_{2}$ de $4 \mathrm{~g} \mathrm{~L}^{-1} \mathrm{~d}^{-1}$ em um volume de meio de $10 \mathrm{~mL}$ e, em $4 \mathrm{~L}$, o teor médio foi de $0,65 \mathrm{~g}$ BMS $\mathrm{L}^{-1} \mathrm{~d}^{-1}$ e em 20 litros $0,85 \mathrm{~g} \mathrm{~L}^{-1} \mathrm{~d}^{-1}$. $\mathrm{O}$ tipo de cultivo e o manejo influenciam grandemente o acúmulo de $\mathrm{C}$ em qualquer ser autotrófico.

Análise da variância revelou significância para o efeito dos tratamentos na variável teor de nitrogênio (N) na BMS, variando de 2,77 a $6,65 \%$. A espécie T. chuii apresentou maior valor, não diferindo significativamente das espécies $\boldsymbol{C}$. vulgaris, Isochrysis sp., T. pseudonana, N. oculata e T. suecica. A espécie C. muelleri apresentou o menor valor, inferior em 58,34\% da espécie T. chuii (Tabela 4). Apesar do alto valor, a espécie T. chuii, apresentou valor inferior ao reportado por MINOWA et al. (1995) para Dunaliella tertiolecta $(9,8 \%)$. O teor de N na BMS de $\boldsymbol{C}$. vulgaris (Tabela 4) também foi menor aos valores citados por MIAO \& WU (2004) e MIAO et al. (2004) em C. protothecoides.

Houve significância nos tratamentos para teor de hidrogênio $(\mathrm{H})$ na BMS, o qual variou de 4,05 a $6,98 \%$. C. muelleri apresentou menor valor, sendo $41,98 \%$ inferior à espécie $N$. oculata, que apresentou maior teor, não diferindo significativamente de $\mathbf{T}$. chuii, T. suecica e C. vulgaris (Tabela 4). N. oculata apresentou valor maior ao obtido em $\boldsymbol{D}$. tertiolecta por MINOWA et al. (1995). C. vulgaris apresentou valor inferior a C. protothecoides (MIAO \& WU, 2004; MIAO et al., 2004). O teor médio de $\mathrm{H}$ foi 5,42\%, próximo ao valor de $6 \%$ referido para plantas por RAVEN et al. (2001).

$\mathrm{O}$ teor de proteína foi derivado do teor de $\mathrm{N}$ na BMS, utilizando-se o fator de conversão 6,25. Houve significância para tratamentos, sendo o maior teor de proteína encontrado em $\mathbf{T}$. chuii, o qual foi superior às espécies $\boldsymbol{P}$. tricornutum, T. fluviatilis, I. galbana e $\boldsymbol{C}$. Muelleri (Tabela 4). Entretanto, foi inferior ao constatado por MINOWA et al. (1995) para $\boldsymbol{D}$. tertiolecta (63,6\%). Em C. vulgaris obteve-se teor de proteína inferior ao obtido por MIAO \& WU (2004, 2005), em $C$. protothecoides (52,64\%).

Na espécie Chaetoceros sp., RENAUD et al. (1999) encontraram $36,7 \%$ de proteína, com média de $26,3 \%$ para a ordem Bacillariophyceae, $28,15 \%$ para Tetraselmis sp., com média de $29,5 \%$ para Prasinophyceae e 29,5\% para Isochrysis sp., com média de $28,3 \%$ para a ordem Prymnesiophyceae. Valor aproximado foi obtido para Isochrysis sp., com média de 24,49\% para a ordem Prymnesiophyceae (Isochrysis sp. e I. galbana). C. muelleri apresentou valor médio inferior $(17,32 \%)$, cuja média para a ordem Bacillariophyceae foi de $21,70 \%$ e maior para Prasinophyceae (T. suecica e T. Chuii), tendo como média 34,47\%. Teores superiores também foram obtidos por RENAUD et al. (2002), para Isochrysis sp. e Chaetoceros sp., e por CASTRO ARAÚJO \& GARCIA (2005), para Chaetoceros cf. wighamii. Já SÁNCHEZ et al. (2000) obtiveram respectivamente teores semelhantes e inferiores para I. galbana.

Ciência Rural, v.39, n.6, set, 2009. 


\section{Estudando $\boldsymbol{P}$. tricornutum e} Nannochloropsis sp, REBOLLOSO-FUENTES et al. (2001b) e REBOLLOSO-FUENTES et al. (2001a) obtiveram 36,4 e $28,8 \%$ de proteína, respectivamente, valores superiores aos constatados neste estudo (Tabela 4).

Avaliando seis modelos de cultivo do tipo estacionário, LÓPEZ-ELÍAS et al. (2003) encontraram teores de proteína para Chaetoceros sp., variando de 10,81 a 25,52\%. LÓPEZ-ELÍAS et al. (2005) encontraram em C. muelleri teores de proteína variando de 38,6 a $71,7 \%$, em cultivo estacionário protegido, e de 50,1 a $71,7 \%$ ao ar livre. O teor médio de proteína obtido neste estudo para o mesmo gênero está dentro da faixa encontrada por LÓPEZ-ELÍAS et al. (2003), sendo, porém, inferior ao encontrado por LÓPEZ-ELÍAS et al. (2005). Teor superior de proteína foi também obtido por VILCHIS et al. (2004) para C. muelleri. SAAVEDRA \& VOLTOLINA (1994) encontraram teor máximo de proteína de 51,86\% e 31,93\% em Chaetoceros sp., em razão do uso de radiação de 565 e $199 \mu \mathrm{mol} \mathrm{m} \mathrm{m}^{-2} \mathrm{~s}^{-1}$, respectivamente, contrastando o valor de $17,32 \%$ obtido para C. muelleri com radiação de $150 \mu \mathrm{mol} \mathrm{m} \mathrm{m}^{-2} \mathrm{~s}^{-}$ ${ }^{1}$, comprovando a influência da intensidade luminosa na síntese protéica, na síntese e na incorporação de toda e qualquer substância, pois são constituídas por C, o qual é fixado pelo processo fotossintético que é altamente influenciado pela intensidade lumínica.

Comparando os resultados obtidos neste estudo com os resultados apresentados na literatura, percebe-se que, tanto a produtividade, como os teores de $\mathrm{C}, \mathrm{H}, \mathrm{N}$ e proteína, variaram muito dentro da mesma espécie, com as condições em que foram desenvolvidos os cultivos, sejam elas de temperatura, fotoperíodo, intensidade de radiação, meio de cultura, tipo de cultivo, entre outros.

\section{CONCLUSÕES}

As espécies $\boldsymbol{C}$. Vulgaris e $\mathbf{T}$. suecica são menos produtivas. Quando se visa à suplementação alimentar, as espécies C. vulgaris e T. Chuii são consideradas interessantes, uma vez que apresentam altos teores de $\mathrm{C}, \mathrm{N}, \mathrm{H}$ e proteína. As espécies $N$. Oculata, T. pseudonana e $C$. vulgaris apresentam altos teores de $\mathrm{C}$, demonstrando alta capacidade de fixação de carbono.

\section{AGRADECIMENTOS}

Os autores agradecem à PETROBRAS, pelo auxílio financeiro (Projeto no 360/2002), e ao Laboratório de Cultivo de Camarões Marinhos (LCM) da UFSC, pelo fornecimento das cepas.

\section{REFERÊNCIAS}

BROWN, L.M.; ZEILER, K.G. Aquatic biomass and carbon dioxide trapping. Energy Conversion Management, v.34, n.9-11, p.1005-1013, 1993.

CASTRO ARAÚJO, S.; GARCIA, V.M.T. Growth and biochemical composition of the diatom Chaetoceros $\mathrm{cf}$. Wighamii brightwell under different temperature, salinity and carbon dioxide levels. I. Prot, carboidrate and lipids. Aquaculture, v.246, p.405-412, 2005.

FERNÁNDEZ, F.G.A. et al. Outdoor production of Phaeodactylum tricornutum biomass en helical reactor. Journal of Biotechnology, v.103, p.137-152, 2003.

GARCÍA, M.C.C. et al. Mixotrophic growth of the microalga Phaeodactylum tricornutum influence of different nitrogen and organic carbon sources on productivity and biomass composition. Process Biochemistry, v.40, p.297-305, 2005.

GÖKSAN, T. et al. Effects of light path lengths and initial culture density on the cultivation of Chaetoceros muelleri (Lemmermann, 1898). Aquaculture, v.217, p.431-436, 2003.

GUILLARD, R.R.L. Culture of phytoplankton for feeding marine invertebrates. In: SMITH, W.L.; CHANLEY, M.H. (Eds.). Culture of marine invertebrate animals. New York: Plenum, 1975. p.29-60.

KURANO, N. et al. Fixation and utilization of carbon dioxide by microalgal photosynthesis. Energy Conversion. Management, v.36, n.6-9, p.689-692, 1995.

LÓPEZ-ELÍAS, J.A. et al. Mass production of microalgae in six commercial shrimp hatcheries of the Mexican northwest. Aquacultural Engineering, v.29, p.155-164, 2003.

LÓPEZ-ELÍAS, J.A. et al. Indoor and outdoor mass production of the diatom Chaetoceros muelleri in a mexican commercial hatchery. Aquacultural Engineering, v.33, p.181-191, 2005. Disponível em: <http://www.sciencedirect.com/science?>. Acesso em: 24 out. 2005. Doi: 10.1016/j.aquaeng.2005.01.001.

MASAKAZU, M.; IKENOUCHI, M. The biological $\mathrm{CO}_{2}$ fixation and utilization project by rite (2) - Screening and breeding of microalgae with High Capability in fixing $\mathrm{CO}_{2}$. Energy Conversion Management, v.38, p.S493-S497, 1997.

MIAO, X. et al. Fast pyrolysis of microalgae to produce renewable fuels. Journal of Analytical and Applied Pyrolysis, v.71, p.855-863, 2004.

MIAO, X.; WU, Q. High yield bio-oil production from fast pyrolysis by metabolic controlling of Chlorella protothecoides. Journal of Biotechnology, v.110, p.85-93, 2004.

MIAO, X.; WU, Q. Biodiesel production from heterotrophic microalgal oil. Bioresource Technology,,v.97, p.841-846, 2006. Disponível em: <www.sciencedirect.com>. Acesso em: 16 jul. 2005. Doi: 10.1016/j.biortech.2005.04.008.

MINOWA, T. et al. Oil production from algal cells of Dunaliella tertiolecta by direct thermochemical liquefaction. Fuel, v.74, n.12, p.1735-1738, 1995. 
MINOWA, T.; SAWAYAMA, S. A novel microalgal system for energy production with nitrogen cycling. Fuel, v. 78, n. p. 1213-1215, 1999.

NIEVES, M. et al. Growth and biomass production of Tetraselmis suecica and Dunaliella tertiolecta in standard medium added with three products of zeolitic nature. Aquacultural Engineering, v.32, p.403-410, 2005.

OLAIZOLA, M. Commercial development of microalgal biotechnology: from the test tube to the marketplace. Biomolecular Engineering, v.20, p.459-466, 2003.

RAVEN, P.H. et al. Biologia vegetal. 6.ed. Rio de Janeiro: Guanabara Koogan, 2001. 906p.

REBOLLOSO-FUENTES, M.M. et al. Biomass nutrient profiles of the microalga Nannochloropsis sp. Journal of Agricultural and Food Chemistry, v.49, p.2966-2972, 2001 a.

REBOLLOSO-FUENTES, M.M. et al. Biomass nutrient profiles of the microalga Phaeodactylum tricornutum. Journal of Food Biochemistry, v.25, p.57-76, 2001b.

RENAUD, S.M. et al. The gross chemical composition and fatty acid composition of 18 species of tropical Australian microalgae for possible use in mariculture. Aquaculture, v.170, p.147-159, 1999

RENAUD, S.M. et al. Effect of temperature on growth, chemical composition and fatty acid composition of tropical Australian microalgae grown in batch cultures. Aquaculture, v.211, p.195-214, 2002

RICHMOND, A. et al. Efficient use of strong for high photosynthetic productivity: interrelationships between the optical path, the optical population density and cell-growth inhibition. Biomolecular Engineering, v.29, p.229-236, 2003.
ROCHA, J.M.S. et al. Growth aspects of the marine microalga Nannochloropsis gaditana. Biomolecular Engineering, v.20, p.237-242, 2003.

RODOLFI, L. et al. Growth medium recycling in Nannochloropsis sp. Mass cultivation. Biomolecular Engineering, v.20, p.243-248, 2003.

SAAVEDRA, M.P.S.; VOLTOLINA, D. The chemica composition of Chaetoceros sp. (Bacillariophyceae) under different light conditions. Comparative Biochemistry and Physiology, v.1, p.39-44, 1994.

SÁNCHEZ, S. et al. Biomass production and biochemical variability of the marine microalga Isochrysis galbana en relation to culture medium. Biochemical Engineering Journal, v.6, p.13-18, 2000 .

SCRAGG, A.H. et al. Growth of microalgae with increased calorific values in a tubular bioreactor. Biomass and Bioenergy, v.23, p.67-73, 2002

TZOVENIS, I. et al. Optimization of T-ISO biomass production rich in essential fatty acids I. Effect of different light regimes on growth and biomass production. Aquaculture, v.216, p203$222,2003$.

VALENZUELA-ESPINOZA, E. et al. Biomass production and nutrient uptake by Isochrysis aff. Ga (Clone T-iso) cultured with a low cost alternative to the f/2 medium. Aquaculture Engineering, v.20, p.135-147, 1999.

VILCHIS, L.M.C. et al. Growth of Artemia franciscana fed Isochrysis sp. ad Chaetoceros muelleri during its early life stages. Aquaculture Research, v.35, p.1086-1091, 2004.

WATANABE, Y.; SAIKI, H. Development of a photobioreactor incorporating Chlorella sp. for removal of $\mathrm{CO}_{2}$ in stock gas Energy Conversion Management, v.38, p.499-503, 1996. 